\section{STRUCTURAL}

\section{BIOLOGY}

ISSN 2059-7983

\title{
Jean-Luc Ferrer (1964-2020): structural biologist, beamline instrumentation innovator and entrepreneur ${ }^{1}$
}

\author{
Juan C. Fontecilla-Camps ${ }^{\mathrm{a} *}$ and Gérard Bricogne $\mathrm{e}^{\mathrm{b} *}$
}

aMetalloproteins Unit, Structure/Function Relationships of Metalloproteins, Institut de Biologie Structurale EPN Campus CS 10090, 71 avenue des Martyrs, F-38044 Grenoble Cedex 9, France, and ${ }^{\mathbf{b}}$ Global Phasing Ltd, Sheraton House, Castle Park, Cambridge CB3 OAX, United Kingdom. *Correspondence e-mail: juan.fontecilla@ibs.fr, gb10@globalphasing.com

\begin{abstract}
1 The biography section was written by Juan C. Fontecilla-Camps and Gérard Bricogne wrote the section on achievements and legacy.
\end{abstract}

Keywords: Jean-Luc Ferrer; obituaries; structural biology; beamline instrumentation.

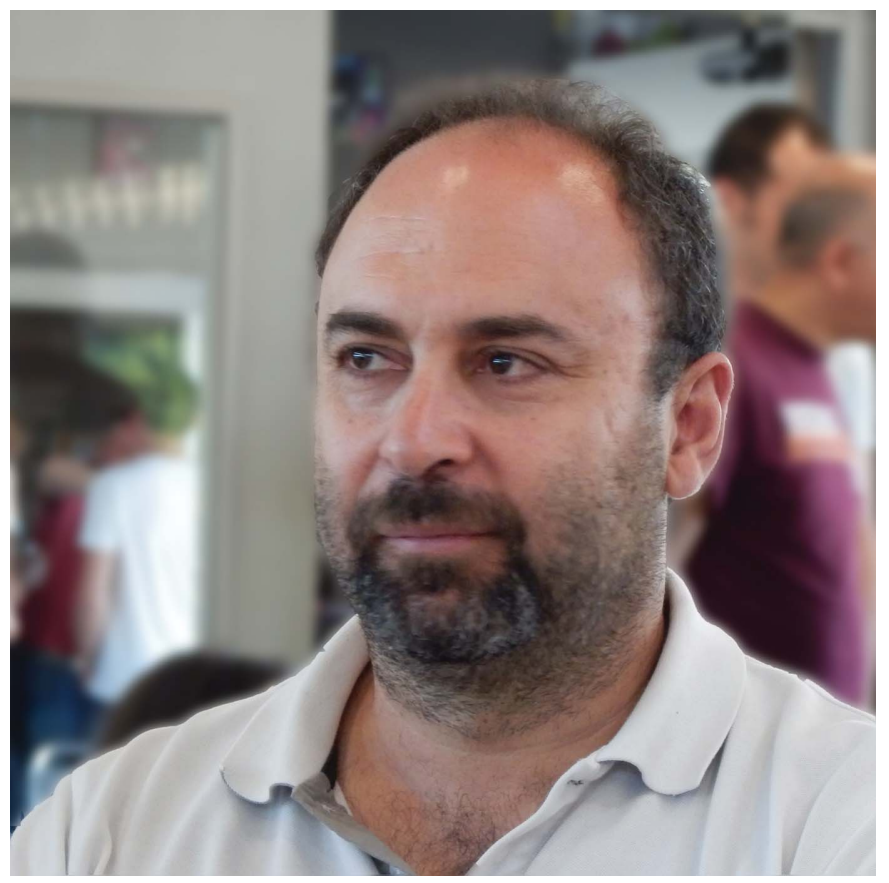

\section{Biography}

Jean-Luc Ferrer studied for his engineering degree from the prestigious Ecole Centrale Paris in 1987. After obtaining a Diplôme d'Etudes Approfondies (DEA) in Physical Chemistry from Université Paris VI, Jean-Luc Ferrer undertook a doctoral thesis in physics on the dynamics of the spectrum of a free-electron laser at the Bruyères-le-châtel research centre of the CEA (Commissariat à l'Energie Atomique). This work enabled him to obtain a doctorate degree from Université Paris XI in 1990 (Iracane \& Ferrer, 1991). At the end of the same year, Jean-Luc was recruited by the Direction des Science du Vivant (DSV) at the CEA in Grenoble and joined the Laboratoire de Cristallographie et Cristallogenèse des Protéines (LCCP). This laboratory, directed by one of us (JCF-C), had just been created by Michel Suscillon, Director of DSV, as part of the Protein 2000 program, to boost the development of structural biology in France. This initiative had been taken following the decision, in January 1989, to build the European Synchrotron Radiation Facility (ESRF) in Grenoble, that became operational in 1994. Once at the LCCP, Jean-Luc joined Michel Roth's team, whose mission was to build the Collaborative Research Group (CRG) French beamline BM02-D2AM. This beamline, 50\% dedicated to protein crystallography, was especially designed to support X-ray multi- and singlewavelength anomalous dispersion (MAD and SAD) data collection (Ferrer et al., 1998).

In 1992, the LCCP joined the Institut de Biologie Structurale (IBS), which resulted from the merging of the CEA's Protein 2000 program with its CNRS counterpart IMABIO. From the very start, Jean-Luc distinguished himself by his interest and skills in 
both the technical and the scientific aspects, sometimes very complex, of beamline construction, and of the determination of protein crystal structures. Concerning the latter, he maintained a very fruitful collaboration with Professor Joseph P. Noel at the Salk Institute (La Jolla, USA), where he spent sabbatical leave in 1996 and 2005. Jean-Luc's work concentrated mainly on the structural biology of phenylpropanoid synthesis in plants: he co-authored 20 papers with Professor Noel on this and related subjects, that were published in prestigious international journals (Ferrer et al., 1999).

After Michel Roth's retirement in 2001, Jean-Luc became head of the new CRG French beamline for protein crystallography BM30A-FIP (Ferrer, 2001). Initially intended as a national platform, the FIP line became over the years an essential tool for both the French and the international communities of protein crystallography. As before, but now with newly acquired responsibilities, Jean-Luc displayed a great deal of creativity, persistence and dynamism in exploiting the advantages of synchrotron radiation for protein crystallography. For example, he was able to anticipate the automation of crystallography beamlines and helped develop, at the ESRF, the first crystal sample loader based on a robotic arm. He also had the excellent idea of using the same robotic arm directly as a goniometer, which, for the first time, allowed $\mathrm{X}$-ray data collection directly from crystals still in the drops of a crystallization plate. This ingenious development paved the way for the in situ crystallographic approach to ligand screening for drug design (Emamzadah et al., 2009; le Maire et al., 2011). In 2009, he ensured the technological transfer of these different innovations by founding the start-up biotechnology company NatX-ray.

Upon the restructuring of the IBS in 2011, Jean-Luc became head of the Synchrotron Group (GSY). As part of the program of the ESRF aimed at creating a new extremely bright X-ray source (EBS), Jean-Luc was able to secure funding towards the rebuilding and upgrading of the FIP beamline in order to continue providing the best possible service to the community. He followed this beamline upgrade project to its end, which will become BM07-FIP2 next autumn when the ESRF reopens.

\section{Achievements and legacy}

Putting Jean-Luc Ferrer's achievements and legacy in a proper perspective requires winding the clock back two decades to the turn of the millennium, when structural genomics (SG) projects were being proposed and set into motion.

SG's aim of harvesting 'low-hanging fruit' (i.e. solving on a massive scale novel structures from easily grown crystals of a good size giving good diffraction) gave a tremendous boost to macromolecular crystallography (MX) infrastructure in general by underwriting coordinated, wide-ranging technological developments and automation efforts (including the necessary invention, standardization and commercialization of new equipment and consumables) that arguably would not have taken place without it, and that laid the technological foundations for the large-scale use of MX in structure-based drug discovery (SBDD). These efforts converged on the operational paradigm of a highly automated workflow structured around the notion of 'one complete dataset from one big crystal per loop in a big beam' that has underpinned much of high-throughput MX for SBDD to this day.

Prior to these initiatives, the numerous successive steps of a typical MX structure determination workflow were carried out by human operators, whose interventions involving decisions or computational tasks were supported by interactive software tools aimed at providing the investigator with the fullest possible exposure to the scientific context and the specific data pertaining to each structure. Indeed, the prevailing standard at the time was that of interactivity through user-friendly GUIs (i.e. in effect 'getting the human into the loop as directly and in as immersive a manner as possible'), in striking contrast to the imperative of complete automation (i.e. 'getting the human out of the loop' as comprehensively as possible) that was being promoted by SG and SBDD.

It is in this context that the French FIP beamline at the ESRF took up the challenge of providing its users with the facilities needed for supporting SG projects. By its very definition, SG involved the de novo determination by experimental (MAD) phasing of large numbers of structures, and the FIP team worked creatively towards the systematic automation of all steps involved in both the alignment of the beamline and its operation in production mode (Roth et al., 2002). JeanLuc Ferrer took the lead in linking existing programs for the sequence of steps involved downstream of data collection itself into a very early instance of what would nowadays be called an auto-processing pipeline directly coupled to a beamline (Ferrer, 2001). The combined resource described by Roth et al. (2002) and Ferrer (2001) was at the time second to none in terms of automated MX. The team maintained its lead by next designing and deploying the CATS robotic sample changer (Ohana et al., 2004) combining a commercial six-axis Stäubli robot with an original design for a combination of 'grips' and 'flipping grips' that enabled the robot to deliver crystals held in both screw-cap and magnetic base vials while keeping them in liquid nitrogen during the entire operation, thus minimizing ice formation and crystal damage. The design of these tools was patented, and the whole technology was transferred to the IRELEC company that went on to sell the CATS sample changer to numerous beamlines around the world (Jacquamet et al., 2009).

In the first wave of automation to which the FIP developments just reviewed belong, the introduction of robots took place in a stepwise manner to provide an exact replacement for the very same actions that were previously performed by the human operator who was being systematically displaced. This was done without any kind of 'refactoring' (i.e. redistribution of functionalities) between those now robotized steps.

A major stumbling block remained in the automated workflows that resulted from this piecewise robotization, viz. the persistent need for human intervention (and hence an obligatory breakpoint in automation) in the harvesting of crystals out of their growth and/or soaking media and their 
conversion to diffraction-ready samples suitable for shipping to a synchrotron beamline, as well as in the subsequent centring in the X-ray beam of the crystal(s) in each sample to enable the collection of diffraction data to proceed. The early anticipation of these impediments had led McPherson to propose the idea of in situ crystallography as early as 2000 in a paper that was truly remarkable for its foresight (McPherson, 2000), and to demonstrate the feasibility of crystal detection by diffraction and limited data collection with a manually assembled crystallization plate on an in-house X-ray source.

Fresh from their experience in harnessing the power of the Stäubli robot to create the CATS sample changer, the FIP team were able to come up with a versatile practical implementation of McPherson's idea by a brilliant piece of 'thinking out of the box': while the other automated sample changers available at the time (Muchmore et al., 2000; Cohen et al., 2002) were based on four-axis robots, the availability of two extra axes on the Stäubli robot, combined with the use of an additional specific plate gripper, made it possible to program the robot arm in such a way as to endow it with the extra functionalities of both a centring stage and a goniometer axis. This then made it possible to screen for diffraction-quality crystals in crystallization drops by directly placing the 96-well crystallization plates themselves in an intentionally broadened synchrotron X-ray beam at room temperature; then using the advanced level of automation already available on the FIP beamline to scan the drops while recording their scattering pattern, looking for Bragg spots to detect whether they contained diffracting crystals; and finally performing a limitedrange $\left(\sim 30^{\circ}\right)$ data collection by rotating a confirmed crystal in the beam.

This refactoring of functionalities shifted the role of robots in the automation process beyond the mere pointwise replacement of human interventions in the traditional human workflow. In the developers' own words (Jacquamet et al., 2004) this new system completely changes the design of the experimental setup by merging functions that were previously considered to be distinct. This radical innovation was hailed as a 'seminal experiment' by the Diamond group (Aller et al., 2015) who have since built a whole beamline (VMX-i) dedicated to in situ crystallography (Sanchez-Weatherby et al., 2019). It also triggered the development of numerous new crystallization plates designed specifically to minimize the $\mathrm{X}$-ray background and increase the rotation angle achievable in such in situ data collection experiments. Last but not least, this work marked a return to considering the potential of room-temperature diffraction experiments, with the increased speed of radiation damage being compensated by the avoidance of the complications and hazards of cryo-protection and by the use of multiple crystals.

Subsequent further elaborations of advanced modes of use of the Stäubli robot arm produced the G-Rob (for Goniometer Robot) (Heidari Khajepour et al., 2013a,b), while the replacement of its sixth axis by an air-bearing goniometer axis to reduce the size of its sphere of confusion led to the RoboDiff (Nurizzo et al., 2016), a key constituent of the ESRF MASSIF-1 fully automated beamline (Bowler et al., 2015).
Original developments based on the G-Rob continued at the FIP beamline with the design of a versatile Visualization Bench (Heidari Khajepour et al., 2013a) and with the robotic harvesting of crystals it made possible (Heidari Khajepour et al., 2013b), establishing a seamless connection between harvesting and data collection through a Crystal Listing capability that circumvented the need to subsequently centre each crystal in the conventional way. In a separate line of developments, the needs of SBDD for a human-free, fully automated means of exposing crystals to ligands prior to highthroughput compound screening by in situ diffraction were considered in a collaboration with a group in Montpellier, which led to the further innovation of 'dry soaking' (le Maire et al., 2011; Gelin et al., 2015). The technological know-how embodied in the G-Rob was patented in 2008 by the French CEA, with Jean-Luc Ferrer and his prominent FIP team member Lilian Jacquamet (deceased 2007) as joint inventors, and served as the basis for the creation in 2009 of the NatX-ray start-up company by Jean-Luc himself, Nathalie Larive and Xavier Vernède.

During the past few years, Jean-Luc and his team returned to the need to provide access to the capabilities of the FIP beamline to users located anywhere in the world in the most flexible and integrated manner possible, and were front runners in doing so through a web-based user interface. WIFIP was released in September 2015 and made FIP one of the very first beamlines offering the full remote control of an MX experiment through an interface based entirely on web services (Sallaz-Damaz \& Ferrer, 2017).

It is worth noting that the totally different context of structural biology's pursuit of X-ray structure determination for ever more challenging targets (i.e. high-hanging fruit) led to parallel developments along the seemingly very different track of micro-crystallography, with its distinct emphasis on micro-beams, rapid sample micro-positioners and nextgeneration X-ray sources. These developments, however, shared the same requirement for automated handling of small and fragile crystals as those that led to in situ crystallography and for refactoring the diffraction experiment away from its traditional 'one complete dataset from one crystal' paradigm. This common concern resulted in a substantial degree of convergence between these distinct tracks: ultimately, the exciting recent development of serial crystallographic experiments on micro-crystals held on fixed-target microfabricated sample grids and shifted at great speeds by highaccuracy micro-positioners (see e.g. Roedig et al., 2016; Cohen et al., 2014; Baxter et al., 2016; Owen et al., 2017) can be seen as an extrapolation and miniaturization of the original experiment by the FIP group [see Fig. 7 in Jacquamet et al. (2004)], adapted to micro-crystals and to next-generation X-ray sources.

In summary, the last two decades have seen strongly innovative and distinguished contributions from Jean-Luc Ferrer and his FIP team. In spite of the modest resources available to him, he produced ground-breaking and highly influential advances in the technologies now being deployed on an unprecedented scale to search for drugs against SARS-CoV-2 
replication enzymes and thus limit the worldwide impact of COVID-19. His success emanated from his wholehearted commitment to structural biology, from his daring initiatives based on the strong engineering background he put to the service of that commitment and, last but not least, from his determination to disseminate his innovations through entrepreneurship, undeterred by the bureaucratic complexities surrounding technology transfer procedures from public research organizations into the private sector. It is a great loss to the MX community that he passed away so prematurely.

\section{References}

Aller, P., Sanchez-Weatherby, J., Foadi, J., Winter, G., Lobley, C. M. C., Axford, D., Ashton, A. W., Bellini, D., Brandao-Neto, J., Culurgioni, S., Douangamath, A., Duman, R., Evans, G., Fisher, S., Flaig, R., Hall, D. R., Lukacik, P., Mazzorana, M., McAuley, K. E., Mykhaylyk, V., Owen, R. L., Paterson, N. G., Romano, P., Sandy, J., Sorensen, T., von Delft, F., Wagner, A., Warren, A., Williams, M., Stuart, D. I. \& Walsh, M. A. (2015). Application of in situ Diffraction in High-Throughput Structure Determination Platforms. In Structural Proteomics: High-Throughput Methods, edited by R. J. Owens, pp. 233-253. New York: Springer.

Baxter, E. L., Aguila, L., Alonso-Mori, R., Barnes, C. O., Bonagura, C. A., Brehmer, W., Brunger, A. T., Calero, G., Caradoc-Davies, T. T., Chatterjee, R., Degrado, W. F., Fraser, J. M., Ibrahim, M., Kern, J., Kobilka, B. K., Kruse, A. C., Larsson, K. M., Lemke, H. T., Lyubimov, A. Y., Manglik, A., McPhillips, S. E., Norgren, E., Pang, S. S., Soltis, S. M., Song, J., Thomaston, J., Tsai, Y., Weis, W. I., Woldeyes, R. A., Yachandra, V., Yano, J., Zouni, A. \& Cohen, A. E. (2016). Acta Cryst. D72, 2-11.

Bowler, M. W., Nurizzo, D., Barrett, R., Beteva, A., Bodin, M., Caserotto, H., Delagenière, S., Dobias, F., Flot, D., Giraud, T., Guichard, N., Guijarro, M., Lentini, M., Leonard, G. A., McSweeney, S., Oskarsson, M., Schmidt, W., Snigirev, A., von Stetten, D., Surr, J., Svensson, O., Theveneau, P. \& MuellerDieckmann, C. (2015). J. Synchrotron Rad. 22, 1540-1547.

Cohen, A. E., Ellis, P. J., Miller, M. D., Deacon, A. M. \& Phizackerley, R. P. (2002). J. Appl. Cryst. 35, 720-726.

Cohen, A. E., Soltis, S. M., González, A., Aguila, L., Alonso-Mori, R., Barnes, C. O., Baxter, E. L., Brehmer, W., Brewster, A. S., Brunger, A. T., Calero, G., Chang, J. F., Chollet, M., Ehrensberger, P., Eriksson, T. L., Feng, Y., Hattne, J., Hedman, B., Hollenbeck, M., Holton, J. M., Keable, S., Kobilka, B. K., Kovaleva, E. G., Kruse, A. C., Lemke, H. T., Lin, G., Lyubimov, A. Y., Manglik, A., Mathews, I. I., McPhillips, S. E., Nelson, S., Peters, J. W., Sauter, N. K., Smith, C. A., Song, J., Stevenson, H. P., Tsai, Y., Uervirojnangkoorn, M., Vinetsky, V., Wakatsuki, S., Weis, W. I., Zadvornyy, O. A., Zeldin, O. B., Zhu, D. \& Hodgson, K. O. (2014). Proc. Natl Acad. Sci. USA, 111, 17122-17127.
Emamzadah, S., Petty, T. J., De Almeida, V., Nishimura, T., Joly, J., Ferrer, J.-L. \& Halazonetis, T. D. (2009). Acta Cryst. D65, 913920.

Ferrer, J.-L. (2001). Acta Cryst. D57, 1752-1753.

Ferrer, J.-L., Jez, J. M., Bowman, M. E., Dixon, R. A.\& Noel, J. P. (1999). Nat. Struct. Biol. 6, 775-784.

Ferrer, J.-L., Simon, J.-P., Bérar, J.-F., Caillot, B., Fanchon, E., Kaikati, O., Arnaud, S., Guidotti, M., Pirocchi, M. \& Roth, M. (1998). J. Synchrotron Rad. 5, 1346-1356.

Gelin, M., Delfosse, V., Allemand, F., Hoh, F., Sallaz-Damaz, Y., Pirocchi, M., Bourguet, W., Ferrer, J.-L., Labesse, G. \& Guichou, J.F. (2015). Acta Cryst. D71, 1777-1787.

Heidari Khajepour, M. Y. H., Lebrette, H., Vernede, X., Rogues, P. \& Ferrer, J.-L. (2013a). J. Appl. Cryst. 46, 740-745.

Heidari Khajepour, M. Y., Vernede, X., Cobessi, D., Lebrette, H., Rogues, P., Terrien, M., Berzin, C. \& Ferrer, J.-L. (2013b). Acta Cryst. D69, 381-387.

Iracane, D. \& Ferrer, J. L. (1991). Phys. Rev. Lett. 66, 33-36.

Jacquamet, L., Joly, J., Bertoni, A., Charrault, P., Pirocchi, M., Vernede, X., Bouis, F., Borel, F., Périn, J.-P., Denis, T., Rechatin, J.L. \& Ferrer, J.-L. (2009). J. Synchrotron Rad. 16, 14-21.

Jacquamet, L., Ohana, J., Joly, J., Borel, F., Pirocchi, M., Charrault, P., Bertoni, A., Israel-Gouy, P., Carpentier, P., Kozielski, F., Blot, D. \& Ferrer, J.-L. (2004). Structure, 12, 1219-1225.

Maire, A. le, Gelin, M., Pochet, S., Hoh, F., Pirocchi, M., Guichou, J.F., Ferrer, J.-L. \& Labesse, G. (2011). Acta Cryst. D67, 747-755.

McPherson, A. (2000). J. Appl. Cryst. 33, 397-400.

Muchmore, S. W., Olson, J., Jones, R., Pan, J., Blum, M., Greer, J., Merrick, S. M., Magdalinos, P. \& Nienaber, V. L. (2000). Structure, 8, R243-R246.

Nurizzo, D., Bowler, M. W., Caserotto, H., Dobias, F., Giraud, T., Surr, J., Guichard, N., Papp, G., Guijarro, M., Mueller-Dieckmann, C., Flot, D., McSweeney, S., Cipriani, F., Theveneau, P. \& Leonard, G. A. (2016). Acta Cryst. D72, 966-975.

Ohana, J., Jacquamet, L., Joly, J., Bertoni, A., Taunier, P., Michel, L., Charrault, P., Pirocchi, M., Carpentier, P., Borel, F., Kahn, R. \& Ferrer, J.-L. (2004). J. Appl. Cryst. 37, 72-77.

Owen, R. L., Axford, D., Sherrell, D. A., Kuo, A., Ernst, O. P., Schulz, E. C., Miller, R. J. D. \& Mueller-Werkmeister, H. M. (2017). Acta Cryst. D73, 373-378.

Roedig, P., Duman, R., Sanchez-Weatherby, J., Vartiainen, I., Burkhardt, A., Warmer, M., David, C., Wagner, A. \& Meents, A. (2016). J. Appl. Cryst. 49, 968-975.

Roth, M., Carpentier, P., Kaïkati, O., Joly, J., Charrault, P., Pirocchi, M., Kahn, R., Fanchon, E., Jacquamet, L., Borel, F., Bertoni, A., Israel-Gouy, P. \& Ferrer, J.-L. (2002). Acta Cryst. D58, 805814.

Sallaz-Damaz, Y. \& Ferrer, J.-L. (2017). J. Synchrotron Rad. 24, $1105-$ 1111.

Sanchez-Weatherby, J., Sandy, J., Mikolajek, H., Lobley, C. M. C., Mazzorana, M., Kelly, J., Preece, G., Littlewood, R. \& Sørensen, T. L.-M. (2019). J. Synchrotron Rad. 26, 291-301. 